Revista internacional de fronteras, territorios y regiones / International Journal of Borders, Territories and Regions

FRONTERA NORTE VOL. 31, ART. 9, 2019

http://dx.doi.org/10.33679/rfn.v1i1.2035

\title{
Cambios en las dinámicas de compraventa y uso de drogas. Un análisis generacional para Hermosillo, Sonora
}

\section{Changes in the Dynamics of Drug Dealing and Use. A Generational Analysis for Hermosillo, Sonora}

\author{
Angélica María Ospina Escobar ${ }^{1}$
}

\begin{abstract}
RESUMEN
El artículo examina cambios generacionales en las formas de vinculación entre delincuencia organizada y varones con uso problemático de drogas en Hermosillo, Sonora. Para ello, se reconstruyen narrativas biográficas que relacionan el tiempo individual de los varones participantes con el tiempo histórico de la producción y tráfico de drogas ilegales en México y el tiempo social de los cambios socioeconómicos experimentados en Hermosillo entre 1970 y 2016.
\end{abstract}

Palabras clave: 1. delincuencia organizada, 2. jóvenes, 3. drogas, 4. norte de México, 5. Hermosillo.

\section{ABSTRACT}

The article examines generational changes in the links between organized crime and male problem drug users in Hermosillo, Sonora. To this end, biographical narratives are reconstructed that establish links between participating males' individual life stories, the timeline of illegal drug production and trafficking in Mexico, and the social timeline of the socioeconomic changes experienced in Hermosillo between 1970 and 2016.

Keywords: 1. Organized crime, 2. youth, 3. drugs, 4. northern Mexico, 5. Hermosillo.

Fecha de recepción: 15 de junio de 2018

Fecha de aceptación: 22 de octubre de 2018

\footnotetext{
${ }^{1}$ Programa de Política de Drogas. Centro de Investigación y Docencia Económica (CIDE), México, angelicaospinae@gmail.com; https://orcid.org/0000-0003-0768-5252
} 
2 Cambios en las dinámicas de compraventa y uso de drogas. Un análisis generacional... Ospina Escobar, A. M.

\section{INTRODUCCIÓN ${ }^{2}$}

Los temas del uso problemático de drogas y de mercados de droga y renta criminal suelen analizarse de manera aislada. Respecto al uso problemático de drogas, prevalecen perspectivas que enfatizan en la denominada "inadecuación del yo" (Reguillo, 2010), desde las cuales se plantea la existencia de factores individuales predisponentes frente a "las adicciones", sin discutir críticamente el papel que juegan las condiciones estructurales en ellas, ni los significados que pueden tener el uso de drogas por parte de los sujetos que las usan. Por su parte, el tema de los mercados de drogas ilegales suele analizarse desde niveles meso y macro, con una tendencia a enfocarse en las violencias que genera el fenómeno. En este artículo planteo la necesidad de vincular ambos niveles de análisis (micro y meso) para develar cómo afectan las políticas de seguridad las condiciones de salud de las poblaciones $\mathrm{y}$, particularmente, de qué forma cambios en las dinámicas de los mercados locales de drogas impactan las trayectorias individuales de uso.

Específicamente, describo cómo las condiciones socioeconómicas de la ciudad de Hermosillo, las escisiones al interior de las organizaciones de delincuencia organizada ${ }^{3}$ y sus dinámicas emergentes, junto con la insuficiencia de programas públicos de atención a las adicciones, generaron, por un lado, un mercado local de metanfetamina y heroína que incentivó el aumento del uso intenso de estas sustancias, sin que hubiera alternativas de reducción de daños o de acceso a servicios públicos de tratamiento. Por otro lado, la mayor presencia de grupos de delincuencia organizada en los espacios de las colonias, favorecieron condiciones para la configuración de carreras delictivas por parte de jóvenes pobres que tenían un uso problemático de drogas, para quienes el mercado de drogas ilegales constituyó una opción de sobrevivencia, ascenso social y obtención de respeto frente a sus pares. En este escenario, se incrementan los riesgos y daños asociados al uso de drogas, causando entre otras cosas, mayores niveles de marginación y exclusión social, así como patrones más intensos y riesgosos de uso de drogas.

El documento está organizado en cinco partes. En la primera se presenta la perspectiva teórica desde la cual se aborda el tema del uso problemático de drogas y su relación con la delincuencia organizada. La segunda parte describe la estrategia metodológica a partir de la

\footnotetext{
${ }^{2}$ Este artículo fue elaborado con el apoyo de UNAM. Programa de Becas Posdoctorales de la UNAM. Becaria del Instituto de Investigaciones Sociales, asesorada por la doctora Marina Ariza.

3 Marisol Ochoa (2017) plantea la dificultad de definir conceptualmente el término "delincuencia organizada" por el dinamismo de la actividad criminal, que modifica sus modos de operar y de organizarse, surgiendo constante nuevas intervenciones y modalidades delincuenciales. El artículo 16 de la Constitución Mexicana, define la delincuencia organizada como "una organización de hecho de tres o más personas, para cometer delitos en forma permanente o reiterada, en los términos de la ley de la materia". Uso indistintamente los términos crimen organizado y delincuencia organizada para referirme a grupos delictivos dedicados a la producción y comercialización de drogas ilegales.
} 
cual se recogió y analizó el material empírico. Seguidamente, se presenta el contexto más amplio en el que los participantes del estudio configuraron sus trayectorias delictivas y de uso de drogas. Posteriormente, se presentan tres relatos biográficos de tres varones que usan drogas pertenecientes a tres generaciones distintas, que muestran cómo ha cambiado la vinculación de los participantes con la criminalidad.

El artículo concluye planteando que las reorganizaciones efectuadas por el mundo criminal para responder a las estrategias del Estado para erradicarlo, junto con el estigma social construido en torno a la figura del "adicto", favorecen la incorporación de jóvenes pobres con uso problemático de drogas en los eslabones más bajos de las agrupaciones criminales, exponiéndolos en mayor medida a la violencia y la muerte al tiempo que legitima el control social de jóvenes pobres a través de estos dispositivos de muerte, al construirlos socialmente como sujetos "inadecuados" para el sistema, en otras palabras, población excedente.

\section{EL ESTIGMA COMO ESTRATEGIA DE CONTROL SOCIAL}

El uso de drogas es concebido aquí como una práctica sociocultural cuyos significados y consecuencias están imbricados en un complejo entramado de condiciones sociales, económicas, políticas, históricas y culturales que se entretejen en las biografías de los sujetos. El uso de drogas es entonces una práctica diversa y cambiante, cuyos significados, representaciones y dinámicas cambian en el tiempo, ajustándose a transformaciones en los marcos socioculturales, a la disponibilidad de las sustancias en los mercados, a los tipos de sociabilida(des) que se construyen en torno a ellas y a las condiciones biográficas particulares de los sujetos.

Los efectos del uso de drogas en las biografías de los sujetos tampoco son homogéneos, están mediados por la condición de clase y género de las personas usuarias y las mediaciones que éstas construyen con la sociedad convencional, desde donde se sanciona el uso de drogas en tanto atenta con las expectativas culturales, ligadas a los valores de la productividad y racionalidad que derivan del capitalismo como forma de organización social (Romaní, 2010).

En estos términos, es en la interacción entre sujetos y/o grupos sociales que ocupan lugares distintos en la estructura social, y entre quienes se distribuye desigualmente el poder, que el uso de drogas se construye como práctica transgresora y que el transgresor es etiquetado y eventualmente estigmatizado (Link y Phelan, 2001).

El estigma, de acuerdo a Goffman (2006), es resultado de relaciones sociales en las que una característica del sujeto se convierte en un atributo desacreditable. Siguiendo a Link y Phelan (2001), la construcción del estigma requiere de la coocurrencia de etiquetamiento, esterotipización, separación, pérdida de estatus, discriminación y ejercicio del poder. Estos mecanismos son mutuamente reforzantes e intercambiables, sin embargo, es el ejercicio del poder de un grupo sobre otro lo que posibilita la creación del estigma. 
La estigmatización efectiva a través de la figura del "adicto", legitima procesos de discriminación y exclusión social, generando una nueva condición de desigualdad en el acceso a oportunidades que se superpone con otras preexistentes (género, clase, etnia, etcétera), profundizando la desventaja social y despojando, en el caso de los sujetos participantes de este estudio, del escaso capital que tenían a su alcance y de los medios para hacerlo efectivo, agudizando "la espiral de descapitalizaciones y de acumulación de desventajas (materiales y simbólicas)" (Reguillo, 2010, p. 396) a lo largo de su curso de vida. Es en el marco de este proceso, que la vinculación a grupos con prácticas violentas o delictivas adquiere un sentido, al tiempo que cambia las experiencias de uso de drogas y los significados asociados a ellas, generando nuevas condiciones que potencialmente profundizan la dependencia a las sustancias.

La hipótesis que desarrollo en este texto es que el uso problemático de drogas, y la posterior vinculación a grupos de delincuencia organizada, son resultado de la tensión que produce en los participantes de este estudio la internalización de un marco de referencia aspiracional -que enfatizan el éxito monetario, el ascenso social y el consumo como ideales de bienestar-, y las dificultades para lograr tales metas a través de las vías institucionales o de los modos socialmente aceptados, debido a su lugar subordinado en la estructura de oportunidades (Merton, 1995 [1938]). ${ }^{4}$

Ello no significa que exista una relación mecánica entre pobreza y violencia, ilegalidad y/o uso problemático de drogas, antes bien, este análisis procura evidenciar cómo se va conformando en la ciudad estudiada tal contexto de tensión estructural, enmarcado por el vacío institucional, el agravamiento de las condiciones de exclusión social y por la expansión de la delincuencia organizada (Reguillo, 2012a). El objetivo de las narrativas construidas es mostrar cómo las biografías de los narradores se vieron interpeladas de maneras distintas, según su generación, por cada uno de estos elementos, y cómo es la compleja relación entre subjetividades y contexto, lo que conforma el escenario propicio para el reclutamiento eficaz por parte de grupos de delincuencia organizada "de jóvenes desencantados, empobrecidos y en busca de reconocimiento" (Reguillo, 2012a, p. 40).

\section{MATERIAL Y MÉTODOS}

La población de estudio son varones que se han inyectado drogas ilegales al menos una vez en el mes previo a la entrevista, residentes en Hermosillo, Sonora. Por las características de la población, es un muestreo de casos críticos (Martínez Salgado, 2012) y como tal, constituyen los usuarios más estigmatizados y vulnerabilizados del universo diverso de usuarios de drogas ilegales en México. Esta selección de casos extremos obedece al interés por comprender lo que en su momento se llamó "contextos de riesgo al VIH", en el marco de una investigación más amplia donde el énfasis estaba en analizar las características

${ }^{4}$ El concepto de estructura de oportunidades "designa la escala y distribución de condiciones que proveen varias probabilidades para que individuos y grupos actuantes alcancen resultados especificables" (Merton, 1995 [1938], p. 25) 
estructurales que facilitan la alta prevalencia de VIH observada entre personas que se inyectan drogas (PID) en esta ciudad.

Los datos que aquí analizo fueron recogidos a través de un ejercicio etnográfico de observación participante en espacios de encuentro de PID entre enero de 2010 y diciembre de 2012 en Hermosillo. Este ejercicio me permitió construir relaciones de confianza con los participantes y, al mismo tiempo, caracterizar a la población, conocer sus espacios de encuentro y sus dinámicas de socialización. En 2014 seleccioné los espacios de encuentro que mayor volumen de PID atraían, con la finalidad de profundizar en las prácticas de socialización y uso de drogas que favorecían la transmisión del VIH. Estos espacios eran habitados principalmente por varones, por lo que decidí enfocar el análisis en ellos, pues se hizo evidente que las mujeres tenían dinámicas distintas de uso de drogas. Así mismo, las prácticas de socialización de las mujeres en grupos de pares y sus formas de vinculación a grupos de delincuencia organizada son distintas de las de los varones y por ello, consideré que merecían un estudio a profundidad diferenciado.

Los espacios seleccionados se ubicaban cerca de lugares de compraventa y uso de drogas al norte de la ciudad. El trabajo etnográfico consistió en realizar visitas semanales en jornadas de 10 a.m. a 7 p.m. El acceso a estos espacios fue facilitado por PID con quienes se había establecido una relación previa. Estar en los lugares me permitía ver el movimiento alrededor de los espacios de compraventa y uso de drogas y participar en conversaciones informales sobre la diversidad de temas que conforman la cotidianidad de los participantes. Esta presencia cotidiana ayudó a conocer mejor las colonias y a otros actores sociales y comunitarios con quienes también establecí conversaciones informales dirigidas a ampliar la comprensión de la historia del sector, los cambios en las dinámicas de compraventa y uso de drogas y los conflictos comunitarios asociados a ellas. Toda la información fue sistematizada en diarios de campo, que hicieron parte del análisis.

Adicionalmente, se recogieron trece relatos biográficos entre los varones que cotidianamente habitaban los espacios seleccionados, usando una entrevista en profundidad basada en la frase "Cuéntame cómo ha sido tu historia con las drogas desde que empezaste hasta ahora", con la que se buscaba suscitar un relato libre en torno a las biografias individuales que permitiera reconstruir detalladamente las trayectorias de uso de drogas, y su relación con otras trayectorias vitales, así como las dinámicas de compraventa y uso de drogas. La muestra teórica fue estratificada por cohorte de nacimiento o generación (1960, 1980, 1990), buscando con ello tener elementos suficientes para ilustrar características cambiantes de las dinámicas de compra-venta-uso de drogas de cada generación. Cada generación responde -como se explicitará en el apartado siguiente- a distintos momentos de la historia de la producción, tráfico y comercialización de drogas ilegales en el país y de la historia socioeconómica de Hermosillo.

Los entrevistados dieron el consentimiento informado para ser entrevistados, y el protocolo de investigación fue aprobado por el Comité de Ética de El Colegio de Sonora. Las entrevistas fueron realizadas en las casas de los participantes y en espacios públicos como parques y cafeterías cercanas a los lugares de encuentro. Todas las entrevistas fueron 
audiograbadas y posteriormente transcritas para su análisis a través de la construcción de relatos biográficos (Bertaux, 1983) organizados por generación.

En términos generales, los participantes del estudio provienen de hogares pobres y, hasta el momento de la entrevista, permanecen en la misma posición social de sus padres, ocupándose principalmente, en oficios manuales de baja calificación. Al comparar por generación, se encuentra que los participantes más jóvenes alcanzaron mayores niveles de escolaridad. El máximo nivel de escolaridad alcanzado es secundaria completa que, aunque es más bajo que el nivel promedio en Sonora (escolaridad promedio de 10 años), corresponde al nivel promedio de escolaridad de la población mexicana (9 años) (XII Conteo General de Población y Vivienda, Inegi, 2015). En cuanto a las trayectorias de uso de drogas, no se observan diferencias generacionales en cuanto a las edades de inicio, pero sí en relación con el tipo de droga. Mientras los nacidos en 1960 se iniciaron todos con inhalantes, ${ }^{5}$ los nacidos en 1980 se iniciaron principalmente con pastillas psicotrópicas y/o marihuana, mientras los nacidos en 1990 se iniciaron con cristal.

Para este artículo, analizo los relatos biográficos de tres participantes en el estudio, uno por cada generación (1960, 1980 y 1990), que estuvieron directamente involucrados en la compra-venta de drogas en Hermosillo. Para cada relato se identificaron temas emergentes que conformaron el análisis del total de datos. Los nombres que se utilizan en el texto no corresponden con los nombres reales de los participantes.

El análisis narrativo, al estar estructurado a manera de una historia que se desarrolla en el tiempo, con un principio y un final, permite tejer de manera minuciosa las relaciones entre el tiempo histórico, el tiempo social y el tiempo individual, ayudando a evidenciar cómo se afectan mutuamente (Chase, 2005). Para ello, el apartado siguiente describe las condiciones socioeconómicas que ha atravesado Hermosillo entre 1970 y el 2000, los cambios documentados en este periodo en las dinámicas de compraventa de drogas ilegales y cómo se han expresado en la ciudad. Posteriormente doy cuenta de cómo esos cambios sociales e históricos impactaron las biografías de cada uno de los participantes, en términos de las drogas a las que tuvieron acceso, el tipo de trayectoria construida y el tipo de relación que establecieron con la delincuencia organizada.

\section{HERMOSILLO, DESIGUALDAD Y DESENCANTO: NOTAS SOBRE EL CONTEXTO SOCIOECONÓMICO Y LA PRODUCCIÓN-TRÁFICO Y COMERCIALIZACIÓN DE DROGAS ILEGALES ENTRE 1970 Y 2016}

El cultivo de amapola en los estados del norte del país y en Sonora, no es un fenómeno reciente. Desde la primera década del siglo $\mathrm{XX}$ se reporta la presencia de cultivos de adormidera (Papaver somniferum, n. común amapola) en distintos municipios a lo largo del

\footnotetext{
${ }^{5}$ El inhalante más popular en México es un pegamento industrial cuyo nombre de marca comercial es "Resistol", nombre genérico de los inhalantes.
} 
estado, ${ }^{6}$ en los primeros años del siglo XX y asociados a la presencia de población china (Astorga, 2015).

La ubicación geográfica de Hermosillo a 107 kilómetros de la costa del Mar de Cortés y a 287 kilómetros de Arizona (Ver mapa 1), entre otras razones, convirtió a esta ciudad desde 1920 en escenario clave para el tráfico de heroína no sólo por su cercanía con el Pacífico, sino también por ubicarse en el paso del ferrocarril ${ }^{7}$ que conectaba a la Ciudad de México con Nogales (Astorga, 2015). Desde entonces, las carreteras que conectaban a Hermosillo con Nogales (ciudad fronteriza entre Sonora y Arizona) y la línea del ferrocarril fueron considerados por agentes norteamericanos como rutas para el tráfico de opio, heroína y marihuana, mientras que Hermosillo era considerada una ciudad con presencia importante de fumadores de opio.

Por su importancia estratégica, a partir de 1920 las campañas de erradicación de cultivos ilícitos tuvieron a Sonora como importante escenario de implementación y se volvieron más frecuentes a partir de 1938 por presión del gobierno estadounidense (Astorga, 2007, 2015). En consecuencia, durante el siglo XX los cultivos de amapola y marihuana fueran trasladándose a lugares más inaccesibles del estado, en la Sierra Madre Occidental, para finalmente concentrarse en el denominado triángulo dorado de la sierra compartida entre Sinaloa, Durango y Chihuahua (Astorga, 2015). Desde 1970, se intensificó la presión a los habitantes de la sierra para el abandono de la siembra y cultivo de marihuana y amapola, proceso que se cristalizó con la "Operación Cóndor" en la zona montañosa del triángulo dorado a final de esa década (Astorga, 2007).

\footnotetext{
${ }^{6}$ Navojoa, Álamos, Huatabampo, Cananea, Agua Prieta y Etchojoa, por citar sólo algunos

${ }^{7}$ Este ferrocarril fue de pasajeros y de carga hasta 1998, momento en que se suspende el transporte de pasajeros. En la actualidad únicamente presta el servicio de carga.
} 
Mapa 1. Ubicación de la ciudad de Hermosillo, Sonora

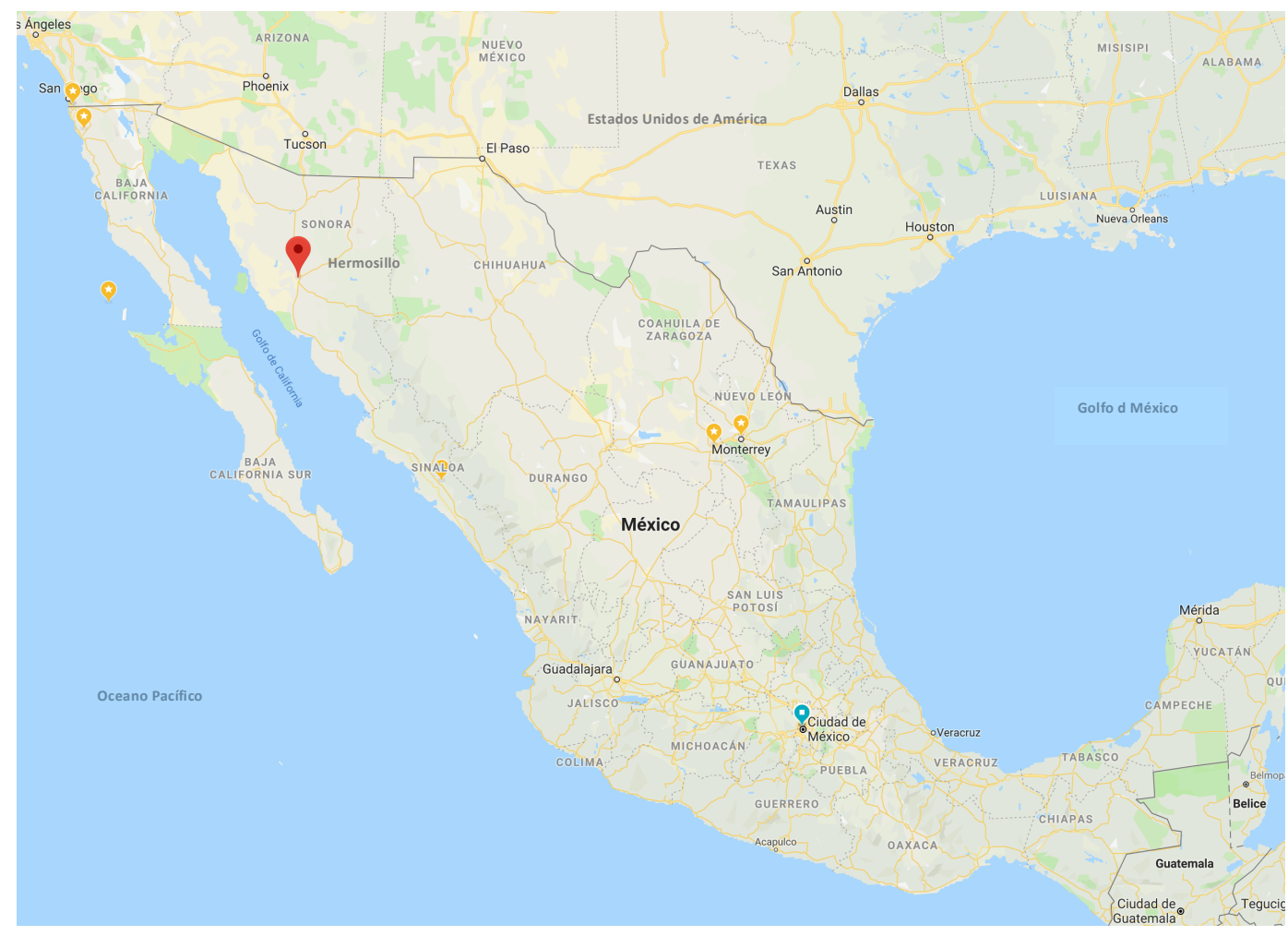

Fuente: Google Maps, 2019.

La década de 1980 fue el momento de mayor crecimiento demográfico de Hermosillo, producto en parte de un éxodo de campesinos empobrecidos que, si bien se había iniciado desde la década de 1950, se intensificó a finales de 1970. Las incursiones militares en las zonas rurales, junto con los conflictos continuados desde principios de siglo por la tierra y el agua (Sanderson, 1981), ${ }^{8}$ fueron algunos de los factores que dieron lugar a este éxodo. Es en 1980, cuando empezaron a conformarse en esta ciudad asentamientos irregulares en la zona norte de la ciudad, que fueron regularizados al final de la década, surgiendo así las colonias donde transcurre la vida de los participantes de este estudio.

Según Covarrubias (1990), los años ochenta en Sonora también se caracterizaron por una notable descapitalización del campo y la consiguiente crisis del sector agropecuario, aunado a un crecimiento de la importancia de la industria, principalmente la maquiladora y la industria automotriz. A pesar de los nuevos empleos creados en la ciudad, es la década con la mayor tasa de desempleo censal $(6.6 \%)$ y con una importante disminución de los sueldos, salarios y prestaciones sociales, lo cual presionó a las familias pobres a aumentar

${ }^{8}$ En 1970 "el valor de los trabajos de irrigación en el estado fue de 400 millones de pesos, de los cuales $0.5 \%$ fue dirigido a unidades de irrigación de menos de cinco hectáreas, $8.5 \%$ a ejidos, el resto a las grandes propiedades: Lo mismo ocurrió con las bombas de agua, 91\% de la inversión fue dirigida a tierras de más de cinco hectáreas" (Sanderson, 1981, p. 150). 
el número de miembros que se dedicaba a actividades informales (Lara Enríquez, 1990, p. 83).

Según Covarrubias (1990), junto con la disminución de la inversión pública en bienestar social, los procesos antes mencionados ocasionaron en la ciudad un aumento de la desigualdad, que se hace más aguda en la década de 1990 y se acompaña de procesos de segregación socioespacial y de discursos de discriminación racional.

En ese contexto, la emergencia de organizaciones criminales dedicadas a la producción, tráfico y comercialización de drogas ilegales en la década de 1980, marcó la transformación de cultivadores de plantas prohibidas en empresarios transnacionales, situación que aumentó de manera exponencial su poder económico y su capacidad para ejercer la violencia y para corromper a los organismos locales y nacionales de control de drogas (Astorga, 2007; Nill Sánchez, 2013). Desde entonces, Hermosillo ha sido uno de los territorios bajo el control del grupo "Cartel de Sonora" y posteriormente fue ocupada por el denominado "Cartel de Sinaloa".

La entrada en vigor del Tratado de Libre Comercio de América del Norte (NAFTA por sus siglas en inglés) y la devaluación del peso mexicano de 1994, marcaron la crisis económica en el campo y las ciudades a finales de 1990. En los noventa, la pobreza y la desigualdad siguió creciendo en Hermosillo y en Sonora. Dos de cada tres empleos generados en el estado fueron informales, y el desempleo llegó al 18\% al final de la década (Camberos y Yáñez, 2003). Aunque se generaron 86000 nuevos empleos, hubo un déficit de $28 \%$ de empleos formales (Covarrubias, 2000). ${ }^{9}$ La población en pobreza aumentó al $52 \%$, de los cuales $12 \%$ vivía en condiciones de pobreza extrema (Camberos, 2000).

En este contexto, aumentó el poder de las organizaciones de traficantes, no sólo porque gracias al NAFTA aumentó el volumen de exportación de drogas a Estados Unidos y se facilitó el lavado de dinero (Payá, 2006), sino porque además se convirtieron en opción laboral para campesinos arruinados por la importación de maíz norteamericano y para jóvenes de sectores populares que no encontraban empleo en las ciudades fronterizas (Knight, 2012).

El aumento del poder de las organizaciones de delincuencia organizada dedicadas al tráfico de drogas, supuso la no subordinación de estos grupos a las autoridades, el inicio de disputas territoriales entre ellos, que se tradujo en el incremento de la violencia en ciudades fronterizas, la creación de mercados locales de drogas a través de la apertura de "tienditas", 10 mediante las cuales, las colonias pobres se convirtieron en escenarios claves de control territorial (García, 2013) y el mayor protagonismo del ejército en las zonas consideradas estratégicas para el tráfico de drogas.

\footnotetext{
${ }^{9}$ Según Covarrubias (2000), debido en parte a la mayor concentración en Hermosillo de actividades económicas de la más alta jerarquía, que demandan fuerza de trabajo con mayor calificación, y un alto nivel de incorporación de procesos intensivos en tecnología.

${ }^{10}$ Espacios para la venta clandestina de drogas en los vecindarios.
} 
La llegada a la presidencia por parte del Partido Acción Nacional (PAN) en el 2000, marcó el fin de la era prí́sta, tras 70 años de gobernanza única en todo el país. Este cambio político generó entre otras consecuencias, la erosión de los canales de mediación y control entre el Estado y las organizaciones criminales (Ríos Contreras, 2012). Adicionalmente, la caída de los precios de la heroína ${ }^{11}$ y la cocaína y la disminución de la demanda de marihuana mexicana en Estados Unidos, agudizaron las disputas territoriales entre grupos de traficantes (García, 2013). Situación que, junto con la descentralización política, ${ }^{12}$ promovió la conformación de ejércitos privados por parte de estos grupos, lo que incrementó a un nivel histórico la violencia en el país (Ríos Contreras, 2012). Los jóvenes pobres fueron actores clave en la conformación de estos ejércitos (Op. Cit.). ${ }^{13}$

En Sonora, el despliegue de las fuerzas armadas para controlar la producción y posteriormente el tráfico y la comercialización de drogas ilegales en los estados protagonistas de estos procesos ha sido constante desde 1940 (Astorga, 2007, 2015). Sin embargo, la mayor capacidad de respuesta de las organizaciones criminales, junto con la menor capacidad del Estado para interlocutar con ellas y controlarlas, se erigió como argumento para aumentar el número de efectivos militares, incrementar su marco de acción y prolongar su presencia en las ciudades en los últimos veinte años. Todo ello en el marco de la reducción de las oportunidades laborales principalmente para los varones jóvenes, ${ }^{14} \mathrm{y}$ el congelamiento o la disminución de los programas sociales dirigidos a este sector poblacional.

Durante el gobierno de Felipe Calderón (2006-2012), también del Partido Acción Nacional, se fortaleció sin precedentes el proceso de militarización de las ciudades, en el marco de la denominada "guerra contra las drogas", que pretendía entre otras cosas, capturar a los jefes de las organizaciones dedicadas a la producción, tráfico y comercialización de drogas ilegales. En este periodo, Sonora tuvo intervenciones militares de manera casi permanente (Atuesta Becerra, 2018). Sin embargo, aún con la mayor

${ }^{11}$ Entre 1992 y 2004 el precio de la heroína cayó en 62\% debido a la entrada de heroína colombiana (Ciccarone, Unick y Kraus, 2009).

${ }^{12}$ El argumento de Ríos Contreras (2012) es que cuando diferentes partidos rigen en diferentes niveles, se crea un ambiente perverso en el que las autoridades de bajo nivel generan pocos y dispersos beneficios por hacer cumplir la ley y, en contraste, las organizaciones criminales ofrecen grandes beneficios a corto plazo a cambio de cooperar con ellas, lo que lleva al crecimiento de estas últimas.

${ }^{13}$ De acuerdo con Reguillo (2012a, p. 40), 67\% de los casos de violencia homicida vinculados a la delincuencia organizada y que acceden a la visibilidad pública, hay participación de jóvenes menores de 25 años y en $49 \%$ de los casos de cuerpos que aparecen como mensajes del poder acumulado de la delincuencia organizada pertenecen a jóvenes.

${ }^{14}$ En Hermosillo, entre 2005 y 2010, los hombres de entre 20 y 24 años tuvieron una tasa de desocupación de 26\% (XII Censo general de población y Vivienda, Inegi, 2010). El porcentaje de población joven sin acceso al trabajo formal, fue de $51.3 \%$ en 2010 y el porcentaje de jóvenes con interés en trabajar, pero sin expectativas de inserción laboral, se duplicó entre 2005 y 2010, pasando de 4.3\% a 9.9\% (Op. Cit). 
presencia militar, en Hermosillo las expresiones de violencia fueron limitadas hasta 2010, momento en que la prensa local empezó a documentar de manera recurrente el asesinato selectivo de personas en espacios públicos a plena luz del día, enfrentamientos entre grupos con armas de alto impacto, secuestros y desapariciones forzadas (Ospina Escobar, 2016).

Es justo en el 2010, que se documenta la disgregación de grupos criminales que estaban bajo el mando de Arturo Beltrán Leyva, abatido en ese año y quien ejercía el monopolio territorial de Hermosillo por parte de la agrupación criminal "Cartel de Sinaloa". A partir de ese momento se reportan aumentos sin precedentes en las tasas delictivas y de homicidios en la capital sonorense. Los homicidios dolosos, por ejemplo, entre 2006 y 2017 pasaron de 39 a 154 (Estadísticas de Mortalidad. Defunciones por homicidios según ciudad de registro, Inegi, 2018a). En 2016, Sonora fue la sexta entidad federativa con mayor tasa de incidencia de delitos por cada 100000 habitantes (42.6) (Incidencia delictiva. Delitos Sentenciados por Entidad Federativa y Municipio, Inegi, 2018b).

La mayor presencia militar que se despliega en el estado a partir de 2006 en el marco de la mal denominada "Guerra contra las drogas", tampoco ha logrado controlar la oferta de drogas en la entidad. Entre 2008 y 2017, el tamaño de los decomisos de metanfetamina por parte de la Secretaría de Defensa Nacional (Sedena) y la Marina pasó de 81 kilos a poco más de 27 000, siendo 2015 el año con mayor número de decomisos registrados (36 000). Sonora fue el quinto estado de la república con mayor número de decomisos de esta sustancia, representando $10.7 \%$ del total nacional y junto con Baja California, representó $70 \%$ de los decomisos de metanfetaminas realizados por la patrulla fronteriza de Estados Unidos entre 2012 y 2016 (Arredondo, 2018).

La presencia militar tampoco ha sido eficiente en la reducción de la demanda de drogas en Sonora, de modo que a 2012 Hermosillo, su capital, se erige como la tercera ciudad del país con mayor volumen de personas que se inyectan drogas, después de Ciudad Juárez y Tijuana (Censida, 2010).

\section{LA EPIDEMIA DE DROGAS INYECTADAS EN HERMOSILLO, SONORA}

Los informes de Sistema de Vigilancia Epidemiológico de las Adicciones (SISVEA) para Sonora, muestran un incremento en la proporción de personas que inician sus trayectorias de uso de drogas con cocaína, metanfetamina y heroína. ${ }^{15}$ Según la encuesta nacional de consumo de drogas en estudiantes (Encode 2014), en Sonora a 2014, 1.3\% de los estudiantes de secundaria y $3.7 \%$ de los de bachillerato habían usado alguna vez cocaína y $0.9 \%$ y $2.6 \%$, respectivamente, habían usado alguna vez metanfetaminas (VillatoroVelázquez et al., 2015).

A partir del 2012, las metanfetaminas y la heroína emergieron como las principales drogas por las cuales las personas acudían a centros de tratamiento. Mientras en 2007, un

${ }^{15}$ Mientras en 2007 el 5.8\%, 2.8\% y 1\% de los usuarios reportan como droga de inicio la cocaína, las metanfetaminas y la heroína respectivamente (SISVEA, 2008), en 2014, fueron $3.6 \%, 2.6 \%$ y $6 \%$ respectivamente (SISVEA, 2015). 
12 Cambios en las dinámicas de compraventa y uso de drogas. Un análisis generacional...

Ospina Escobar, A. M.

$15 \%$ de los usuarios que buscaron ayuda en los centros de tratamiento no gubernamental, reportaron como principal droga de impacto la heroína, a 2009 el porcentaje fue de $24.6 \%$ y se mantuvo en este nivel hasta 2016 fecha de la última encuesta nacional de adicciones. Por su parte, las metanfetaminas fueron reportadas como la principal droga de impacto por el 69\% de las personas adultas que acudieron a centros de tratamiento en 2017 (SISVEA, 2018). En nuestra hipótesis, la importancia creciente del uso de metanfetaminas en Hermosillo, se asocia a la conformación de un mercado local de drogas y al mayor control que ejercen grupos de delincuencia organizada durante la última década en espacios barriales, producto entre otros factores de la fragmentación del denominado "Cartel de Sinaloa".

Los tres relatos que presento a continuación describen cómo los cambios socioeconómicos acaecidos en Hermosillo, junto con las transformaciones en las maneras de operar de las organizaciones criminales dedicadas a la producción, tráfico y comercialización de drogas ilegales, se imbrican en las biografías de distintas generaciones de varones con uso problemático de drogas en Hermosillo aumentando los riesgos asociados al uso de drogas.

\section{DE LA ILEGALIDAD A LA CRIMINALIDAD: TRANSFORMACIONES EN LAS DINÁMICAS DE COMPRAVENTA DE DROGAS EN HERMOSILLO}

\section{Rafael (1965). Un emprendedor bien apadrinado}

Rafael es el segundo de cinco hijos, migrantes de segunda generación del municipio de Banámichi, ubicado cerca de la Sierra Madre Occidental, a 168 kilómetros de Hermosillo. Presenció la construcción de la colonia en la que vive por parte de los pobladores originarios, entre ellos, su familia extendida. Los mismos pobladores presionaron políticamente y participaron en la introducción de los servicios básicos de energía, agua, alcantarillado y pavimentación, por lo que Rafael creció en medio de redes de vecindad caracterizadas por vínculos de compadrazgo y solidaridad. Hijo de madre soltera, fue criado por su abuela materna. La precariedad de sus condiciones de vida lo llevaron a que muy temprano abandonara la escuela y se dedicara a actividades económicas informales para aportar económicamente a su hogar. Ello incentivó la búsqueda constante de oportunidades de generación de ingresos. Conocer a personas que usaban drogas cerca de su casa, tener familiares que usaban y vendían drogas, y ser él mismo usuario de drogas, le permitió tener acceso a las dinámicas de compraventa a temprana edad, de modo tal que a los 13 años inició su trayectoria como distribuidor de drogas entre su grupo de pares en su colonia.

Tres elementos caracterizan el rol de Rafael como distribuidor de drogas: la ausencia de la violencia en las dinámicas de compraventa, el poder de su "padrino"16 en la estructura

\footnotetext{
${ }^{16}$ El "padrino" no se refiere a un vínculo personal de intimidad, sino que se refiere a la persona (o "figura") que le dio acceso a las sustancias para comercializar y que, además, le ofrece protección frente a los agentes de seguridad del Estado (policía y militares) y frente a potenciales competidores.
} 
del gobierno local y su entrada tardía en prisión (a los 37 años). El relato de Rafael muestra un primer momento de la historia de la venta de drogas ilegales en México, caracterizada por el papel central que jugaron algunas autoridades locales en la protección de traficantes locales, a cambio de dinero y obediencia y donde el uso de la violencia no era predominante (Serrano, 2007; Astorga, 2015; Knight, 2012; Ríos Contreras, 2012).

La relación cercana que estableció Rafael con su "padrino" le permitió consolidar su trayectoria como distribuidor de drogas en tanto le brindó acceso a mayor diversidad y mayores volúmenes de sustancias (cocaína, marihuana y pastillas psicotrópicas). Así mismo, a través del "padrino", Rafael tuvo acceso a nuevos lugares (discotecas y centros nocturnos de moda) para distribuir principalmente cocaína, al tiempo que le ofrecía protección frente a policía y los operativos del ejército.

"A través de D. [pareja que se ocupaba como trabajadora sexual en una casa de citas que era propiedad de una tía de Rafael] conocí a mi padrino. Él tenía un puesto importante en la [Policía] Judicial del Estado... He sido suertudo, porque ese ruco ${ }^{17}$ me agarró de su achichintle [ayudante] ... Con él empecé a mover cajas de pastillas y kilos de coca. Me llamaba y me decía, 'morro, ${ }^{18}$ así está el movimiento'. Yo sólo iba a donde me decía, todo el movimiento estaba asegurado, no me paraban los soldados, ni nadie. Él también me decía que fuera a tal o cual centro nocturno o a las discos del momento, donde podía mover la mercancía, y así fui expandiendo el bisnes a otros lugares... Él me dejaba el material, yo lo vendía al precio que me pareciera, dependiendo del paciente [cliente] y le respondía al don por su dinero. [...] El ruco se cuidaba, yo era el que paraba bola [asumía toda la responsabilidad si algo salía mal], él sólo me llamaba y me decía 've allá', 'habla con tal', 'entrégale a tal'..."

La larga duración de esta relación de padrinazgo -cerca de ocho años-, así como la posición que éste ocupaba en la estructura del gobierno ${ }^{19}$ garantizaron que Rafael se mantuviera en el negocio, ampliando constantemente su red de clientes y accediendo a lugares "seguros" para vender drogas. La protección del "padrino" favoreció que Rafael no cayera en prisión ni que tuviera que recurrir a la violencia para defenderse de otros competidores en el mercado.

Después de ocho años de relación, su "padrino" murió a causa de cáncer. Sin la figura protectora del "padrino", Rafael no logró volver a acceder a las cantidades de cocaína, marihuana y pastillas que solía comercializar y perdió acceso a puntos de distribución, lo que redujo sus posibilidades de asegurar el nivel de ingresos que requería para sostener su dependencia a las drogas. En estas condiciones, en 2002, a los 37 años, Rafael cayó en

17 "Ruco" se utiliza en el norte de México de forma coloquial para denominar a "adulto" o un hombre mayor. Similar al "don".

${ }^{18}$ El término "morro" se utiliza el norte de México de forma coloquial para denominar a un menor de edad o a una persona joven.

${ }^{19}$ Según el relato de Rafael se trataba de un jefe administrativo de la Policía Judicial Estatal. 
14 Cambios en las dinámicas de compraventa y uso de drogas. Un análisis generacional...

Ospina Escobar, A. M.

prisión, acusado de delitos contra la salud en modalidad de posesión y venta de heroína y cocaína.

Varios factores incidieron en la detención de Rafael por posesión y venta de drogas. En primer lugar, la falta protección e interlocución frente a un cuerpo policial urgido de mostrar resultados en la lucha contra el "narcotráfico". En segundo lugar, una nueva modalidad de venta de drogas que lo hacía vulnerable, en tanto debía operar una casa de distribución por pedido de un grupo delictivo que empezaba a imponer nuevas reglas para la compraventa de drogas en las colonias del norte de la ciudad ${ }^{20}$ y que operaba a través de “adictos" caídos en desgracia como Rafael, quienes no tenían más remedio que aceptar las condiciones impuestas por este grupo criminal, para acceder a los ingresos necesarios para mantener su dependencia a la heroína.

Su estadía en prisión de seis años le permitió acceder a otras redes delictivas a través de las cuales, después de su excarcelación, pudo volver a conectarse con la compraventa de drogas hasta 2010, momento en que la violencia tocó a su puerta.

“[...] Así estuvimos chambeando hasta que a mediados de 2010 nos levantaron los municipales y nos entregaron a los sicarios... Cuando nos entregan a los sicarios, nos ponen una capucha para que no viéramos y me pegaron una putiza, que de ahí yo me quedé traumado. [...] En un momento recibieron una orden y fueron y nos tiraron en una parte, cuando nos quitaron las capuchas era la Peni."

Los relatos de los participantes dieron cuenta de la llegada alrededor de 2010 de grupos que buscaban controlar la venta de drogas en las colonias del norte de la ciudad. Los pequeños distribuidores que viajaban a Nogales, San Luis Río Colorado en Sonora o a Culiacán en el estado de Sinaloa, a comprar algunos gramos de heroína para revender entre su red de pares, empezaron a ser cooptados por tales grupos. A partir de ese momento, los relatos evidencian también cierta complejización en la relación entre la venta de drogas y la policía. De acuerdo a los relatos, los agentes policiales continuaron persiguiendo y cerrando los lugares de venta de drogas y deteniendo a traficantes y usuarios, pero con la finalidad de favorecer el control del mercado por parte de un grupo delictivo. De esta manera, es recurrente en los relatos biográficos las historias sobre cómo fueron detenidos por parte de policías y luego puestos a disposición de grupos criminales, quienes los interrogaron sobre el origen de las drogas que usaban y/o comercializaban y les dieron el ultimátum sobre dónde y a quién comprar si querían seguir con vida. Después eran liberados o enviados al reclusorio.

Los relatos describen cómo a finales de la primera década del 2000 los grupos que controlaban la venta de drogas les asignaron armas a sus distribuidores, quienes además fueron presionados para que atendieran casas de distribución, espacios donde se podían

${ }^{20}$ En el relato, Rafael cuenta que un "patrón" lo contacta y le ofrece vender drogas en una casa de seguridad, ante la falta de otras opciones, él acepta, sabiendo los altos riesgos de ello. 
conseguir drogas todo el día, todos los días y donde las personas que habían adquirido deudas por drogas eran forzadas a permanecer y realizar alguna labor para pagar su deuda. De este modo, al momento de las entrevistas, la queja recurrente en los participantes era que los distribuidores habían dejado de ser "compas" o pares y respondían más a la lógica de la "organización" para la que trabajaban, pues debían responder por cantidades de dinero y de drogas vendidas. En este contexto, algunos usuarios ${ }^{21}$ se habían convertido en distribuidores de drogas con sueldos y horarios de trabajo, en porteros y vigilantes, aumentando con ello los riesgos de ser judicializados y de morir en enfrentamientos con grupos rivales.

Aurelio (1978): La pandilla como mediador y la construcción del "cholismo" como estilo de vida

Aurelio es el hijo menor de un boxeador alcohólico y una operaria de una de las maquilas de la ciudad. Las difíciles condiciones para acceder y mantenerse en un empleo formal favorecieron que el padre de Aurelio estuviera en condición de desempleado durante la mayor parte de la infancia y adolescencia de este, en la década de 1980. Desempleado, el padre se dedicaba a alcoholizarse, mientras la madre intentaba sacar a flote su hogar con tres hijos menores de edad. La precariedad en las condiciones de vida, junto con la violencia recurrente del padre, fueron factores que coadyuvaron a que Aurelio abandonara tempranamente su hogar y se uniera a la pandilla de su colonia como una estrategia de sobrevivencia.

Para la generación de Aurelio, la colonia es un espacio construido que empieza a ser apropiado por parte de los y las jóvenes que nacen en ella. Las pandillas aparecen a finales de los ochenta como un actor en ese proceso de apropiación del territorio, que ya no pasa sólo por la construcción de la vivienda y adecuación de servicios públicos, sino por enunciar un modo particular de ser joven-habitante de este sector de la ciudad, que será prontamente estigmatizado y criminalizado desde los discursos oficiales y las prácticas institucionales (Valenzuela, 2010), generando con ello mayor resistencia de sus prácticas y mayor cohesión entre sus miembros.

La importancia de las pandillas reside en su capacidad para cargar de sentido las rutinas y estilos de vida, como espacio mediador entre lo público y lo privado (Valenzuela, 2009 , p. 31), como ámbito de seguridad, espacio de contención y estrategia de sobrevivencia en un contexto donde las violencias se fueron haciendo cada vez más presentes y en donde las instituciones eran cada vez menos capaces de construir y transmitir sentidos (Reguillo, 2010, 2012b; Urteaga, 2010; Valenzuela, 2010).

${ }^{21}$ Particularmente aquellos con mayores necesidades económicas y emocionales, elementos que facilitan su aceptación de los requerimientos del grupo armado y aquellos con las habilidades que los grupos criminales requieren (capacidad y/o disposición para ejercer la violencia, conocimiento sobre uso de armas, entre otros). 
En el caso de Aurelio, la pandilla se configuró como una nueva familia, estructurada con normas, misiones, códigos y rangos que ordenaban el mundo de estos jóvenes, donde además disfrutaban de la camaradería y protección de sus pares. En palabras de Valenzuela "las pandillas articulan biografías construidas a partir de similares condiciones de vida y se fortalecen en los mundos de vida compartidos, las experiencias cotidianas, las relaciones cara a cara en defensa del otro" (2010, p. 328).

El ingreso a la pandilla estaba condicionado al cumplimiento de una serie de pruebas que involucraban la participación en actos delictivos (principalmente robos), lo que además posibilitaba, entre otras cosas, el acceso a bienes de consumo que de otra manera quedaban por fuera del alcance de Aurelio.

"Ser cholo era algo chilo ${ }^{22}$ en esa época, algo moderno, era un tipo de vida [...] Era como un símbolo de rebeldía y eso me gustaba [...] Las pandillas defendían los tres puntos famosos de la vida loca. Era un pacto, se podía decir entre barrios, tú dabas la vida por tu barrio, por tu colonia [...] Te podías llegar a sentir orgulloso de tu barrio, porque metían las manos al fuego por ti, brincaban paros [lo defendían] porque si llegaban sobre mí a quererme tumbar, ${ }^{23}$ ahí mero brincaban."

Como bien describe Valenzuela (2009, p. 60) "las pandillas remiten a relaciones intensas conformadas en las edades tempranas que delimitan procesos comunes de socialización, pero se construyen en ámbitos complejos de interacción con otras redes sociales y familiares".

En los relatos de este periodo, la pandilla aparece como un actor mediador entre los jóvenes y otros actores de la escena ilegal en Hermosillo, como por ejemplo, distribuidores de drogas y policías corruptos que vendían armas y drogas. Tanto las armas como las drogas eran propiedad de la pandilla y acceder a ellas requería acercarse a estos grupos juveniles. El uso de armas estaba regulado para unos espacios específicos y estaba reservado para aquellos con mayor estatus en el grupo.

El uso de drogas y los actos delictivos al interior de la pandilla eran acciones colectivas en tanto existía una visión común que orientaba la participación de los individuos y cargaba de un sentido particular dichas prácticas que no pueden ser entendidas sólo desde el lente de la "adicción" o la criminalidad, sino que hacen parte de la forma cómo estos jóvenes se asignan un lugar en el mundo en medio de la exclusión, la criminalización y el riesgo de morir (Valenzuela, 2010).

Las guerras entre pandillas, la mayor visibilización del uso de drogas en las calles y parques de la colonia y la aparición de armas de fuego en los espacios vecinales, junto con la mayor incidencia de robos y riñas entre grupos de jóvenes, empezó a aterrorizar a los

\footnotetext{
22 "Chilo" es una palabra coloquial que se usa en el norte de México para denotar que algo es atractivo, bueno, divertido.

23 "Tumbar" es una palabra que quiere decir robar en la jerga de los jóvenes de contextos urbano-marginales del norte de México.
} 
adultos, quienes dejaron de operar como agentes de regulación y en su lugar, la convivencia se empezó a ver dominada por el temor y el silencio.

Ante la falla de mecanismos de control hacia los comportamientos de los jóvenes, el encierro se convirtió desde los noventa en una alternativa: el ingreso compulsivo a centros de rehabilitación pagados por los familiares y el mayor encarcelamiento de jóvenes de este sector de la ciudad. Junto con otros factores, este mayor etiquetamiento y las prácticas de encierro y criminalización de estos jóvenes varones pobres dificultó su acceso a otras redes de sociabilidad y promovió la profundización de sus trayectorias criminales, así como sus patrones intensos de uso de drogas.

En el caso de Aurelio, adquirir la apariencia de pandillero, irse a trabajar a la sierra en cultivos de marihuana, ${ }^{24}$ desertar y hacer nuevas alianzas con grupos delictivos, junto con la entrada recurrente a prisión, fueron eventos que le permitieron hacerse de una reputación y a través de ella, conocer a personas que facilitaron el acceso a drogas (heroína y metanfetaminas $)^{25}$ para su distribución entre su red de conocidos. Sin embargo, estos eventos marcaron a lo largo de su biografía su marginación y lo fueron descapitalizando frente al mercado más amplio de interacciones con la sociedad convencional.

En 2010 un evento fracturó su trayectoria criminal, forzándolo a desvincularse de la venta de heroína.

"Estaba vendiendo, pero...me reventó [detuvo] la federal. Fue cuando llegó la mafia que está ahora, hace como cinco años... Llegaron y llegaron poniendo el dedo a toda la gente con la que yo chambeaba, todos torcieron. ${ }^{26}$ Se cambiaron a chambear con ellos porque llegaron con arreglos con los federales y se quedaron con la red. [...] Me dijeron que era una advertencia, que si quería entrarle al jale ${ }^{27}$ ya sabía a dónde ir... Decidí que quería vivir y por eso me puse a vender dulces en los camiones, sacrifiqué mi dignidad... A veces me pregunto si valió la pena”.

${ }^{24}$ A finales de los noventa, llegó el rumor a las colonias del norte de la ciudad, a través de los espacios de socialización de las pandillas, que se requería gente para trabajar en cultivos marihuana en la sierra de Chihuahua. Se ofrecían salarios de mil pesos diarios y se disponían de autobuses en las colonias para transportar a los interesados. Decenas de jóvenes de este sector de la ciudad acudieron al llamado, muchos no regresaron. Aurelio se enroló, acaba de salir de prisión y le urgía un "cambio de aire". Desertó cinco meses después por las difíciles condiciones de aislamiento y subordinación que exigían quienes estaban al mando, lo que supuso romper lealtades y construir otras nuevas para poder sobrevivir. Ello marcó su salida de la pandilla y el inicio de su trayectoria delictiva por fuera de ella.

${ }^{25}$ Conocida coloquialmente como cristal, ice, hielo o crico.

${ }^{26}$ En el contexto de esta conversación, "torcer" significa que fueron detenidos.

27 "Jale" es una palabra que en el norte de México significa trabajo, en el contexto de esta conversación, el "jale" hace referencia a la venta de drogas ilegales. 
Vicente (1988): Matar para sobrevivir

"Toda toda mi vida, desde que tengo recuerdo, he sido malandro y he estado con malandros. Mi papá era malandro y me llevaba a sus jales ${ }^{28}$ desde morro. ${ }^{29}[\ldots]$

Cuando él desapareció me empecé a juntar con los viciosos de mi calle. Alli unos camaradas me pusieron una misión para entrar a trabajar con los chilos ${ }^{30}$ [poderosos]. Me dijeron '¿no que muy cabrón?, a ver si es cierto'. Tenía que cargarme ${ }^{31}$ [matar] a un bato ${ }^{32}[\ldots]$ Lo hice y me soltaron coca y cristal para que yo moviera en el barrio [...] Empecé a andar en carro y con pistola ... Fueron buenos tiempos".

A partir de finales de la década de los noventa, la experiencia de sociabilidad en las colonias populares del norte de Hermosillo se caracterizó por menores interacciones con personas de otros sectores sociales, menores oportunidades de salir de la colonia y menor presencia institucional a través de programas sociales. La colonia y la esquina se fueron convirtiendo en lugares cada vez más encerrados y su sociabilidad cada vez más fluida con los eventos de encarcelamiento que fueron no sólo más recurrentes sino también más tempranos entre los jóvenes nacidos a partir de 1990.

Vicente es el mayor de tres hermanos, hijo de un policía corrupto y un ama de casa convertida en mucama de hotel tras la desaparición de su pareja. Fue el padre de Vicente quien lo introdujo tempranamente al mundo de la criminalidad y tras su desaparición se vinculó de manera activa, adoptando el rol de "sicario".

El estilo de vida de "la vida loca" de la pandilla de los jóvenes de las décadas de los ochenta y noventa fue reemplazado por el estilo de vida del "sicario" en el nuevo milenio. Si bien la muerte es la compañera constante desde muy temprano en las biografías de ambas generaciones de jóvenes, mientras los pandilleros encontraban en su grupo un espacio de protección y camaradería, los relatos de los jóvenes nacidos a partir del noventa evidenciaron en mayor medida la soledad y la desconfianza que enfrentan en los vínculos con sus pares, producto de la competencia promovida dentro de las agrupaciones criminales, donde las vidas de estos jóvenes son prescindibles.

La solidaridad de la pandilla de la década anterior fue reemplazada por la "hermandad de malandros y prófugos" que constituyen un mundo mucho más marginal en estos jóvenes "sicarios". Mientras la pertenencia al barrio era el elemento cohesionador de las pandillas de los ochenta, en esta nueva "hermandad de malandros y prófugos", el elemento común es su trayectoria criminal y huir constantemente de "la ley", representada por el Estado y las instituciones policiales, o por los grupos criminales de los que han desertado.

${ }^{28}$ En el contexto de esta conversación, los "jales" hacen referencia a actividades ilegales a las que se dedicaba el padre como extorsión, secuestro y asesinato.

${ }^{29}$ En esta conversación "morro" es una palabra coloquial para denotar niño.

${ }^{30}$ En esta conversación el término "chilos" significa personas poderosas, aquellas que controlaban la venta de drogas.

31 "Cargar" es un eufemismo que usa el entrevistado para nombrar el acto de asesinar a alguien.

32 "Bato" es una palabra coloquial que en el norte de México significa hombre. 
Al mayor despliegue de violencia por parte de los jóvenes se ha correspondido un mayor silenciamiento del mundo adulto. Los adultos de la colonia parecieran vivir presos del miedo hacia los jóvenes, al que responden legitimando las muertes violentas de estos jóvenes, pues "un malandro muerto es un malandro menos". En ese sentido, mientras el encierro se erigió en la década del noventa como estrategia de control de los jóvenes pobres por parte del mundo adulto, en el nuevo milenio el aniquilamiento pareciera ser la nueva estrategia de control.

Adicionalmente, los jóvenes de la generación de Vicente se enfrentaron a una desvinculación social más aguda que la vivida por las generaciones anteriores. Así, aunque Rafael y Aurelio tampoco lograron completar el nivel primario de educación básica, desarrollaron un oficio, que alternaban con sus actividades criminales. Vicente terminó el bachillerato en los tutelares de menores y hasta el momento de la entrevista, nunca tuvo un oficio no ilegal. Tras la desaparición de su padre, fue "adoptado" por el grupo de "malandros" de la esquina de su casa, quienes realizaban para aquel, tareas criminales eventuales.

En este contexto, la policía aparece representada en los relatos biográficos de los varones de las generaciones más jóvenes como un agente más al servicio de la delincuencia organizada, que torturaba, sembraba drogas y acosaba a quienes no contaban con protección por parte de estas organizaciones o no tenían los recursos para pagar sobornos.

Por su parte, la escuela emergió en los relatos biográficos de estos jóvenes nacidos a partir de los noventa como una institución ausente. Estos relatos muestran además unas familias desbordadas, con carencias materiales muy pronunciadas, pero también con una enorme incapacidad para contener y acompañar emocionalmente a sus jóvenes. Por ejemplo, en los relatos de los participantes de esta generación más joven hay una alusión reiterada a cómo sus madres y demás adultos con quienes comparten el hogar no logran "hacerse respetar" y cómo desde muy chicos confrontan abiertamente las dificultades de estos adultos para satisfacer sus necesidades básicas.

En otro nivel, la observación etnográfica permitió constatar que la comunidad barrial se ha convertido en cómplice de las muertes jóvenes, algunas veces a través de la justificación de estas muertes y en otras por un silencio que enrarece la sociabilidad en el marco de una sospecha constante hacia el otro.

Ante este vacío, el grupo pares, pareciera tornarse para los jóvenes nacidos a partir de los noventa en un bastión fundamental para la sobrevivencia. Un grupo en el que las prácticas violentas se tornan centrales como mecanismo de ingreso y ganancia de estatus. La observación etnográfica permitió identificar que las conversaciones en estos espacios giraban casi siempre en torno a los enfrentamientos, secuestros, cobros y ejecuciones en los que han participado. Los más jóvenes escuchaban con atención las hazañas de los más grandes, de aquellos con mayor prontuario criminal y explicitaban su deseo de seguir sus pasos, mostrándose dispuestos a cumplir pruebas que demuestren su lealtad y su capacidad de ejercer la violencia. 
En el caso de Vicente, el arrojo que mostraba al realizar cada una de las tareas encomendadas por el grupo le permitió ir ganando una reputación, que se fue reforzando por sus detenciones recurrentes. En prisión tal reputación se fortalecía, al tiempo que actualizaba sus vínculos delincuenciales, y afianzaba su trayectoria criminal. En prisión conoció a su "patrón", quien lo reclutó como integrante de su grupo criminal, primero, bajo el rol de "burrero", pasando droga por el desierto, después, como "enlace" en un condado de Texas y posteriormente, como miembro de seguridad de comandos armados en el estado de Tamaulipas y en el barrio de Tepito, en la Ciudad de México.

"En Tamaulipas estuve todo el 2010. Fue mi época más loca. Todos andábamos con cuerno de chivo y era pura balacera todos los días. Estábamos siempre "bien arriba", con mucho perico [cocaína], siempre había unos bolsones grandotes de perico, pa' tenernos bien contentos. Ahí vi muchas cosas, vi morir a muchos compas. Vivíamos el día al cien, bien alterados por tanto perico en la cabeza. No dormíamos porque siempre había algo que hacer...puras malosadas..."

La lucha de Vicente contra su marginalidad alimentó su relación de dependencia/sumisión con el grupo criminal para el que trabajaba, pues éste se vislumbraba como la única opción disponible para acceder a los bienes y el estatus que aspiraba. Esa relación dependencia/sumisión, lo hizo además más vulnerable: era más visible, se ocupaba en trabajos de mayor riesgo -como pistolero-, vivió en lugares que no le eran familiares, etcétera; todas estas situaciones erosionaron su escaso capital social, aumentaron el estigma y la discriminación hacia su persona, minando sus posibilidades de conseguir un trabajo legal.

En este escenario, el ritual colectivo del uso de drogas como práctica de desenfado, se reemplazó por un uso individual y compulsivo. Los relatos de las generaciones más jóvenes de participantes describen como consumían grandes cantidades de droga, durante periodos prolongados y cómo estos patrones de consumo les permitían olvidar las atrocidades realizadas, ser funcionales en el grupo, de modo que pudieran no dormir, estar alerta, lo que a su vez los exponía a más riesgos y daños, no sólo de las drogas, sino de las actividades ilegales en las que tenían que participar para aprovisionarse de ellas.

Actualmente han cambiado también las drogas disponibles. Hoy en las colonias ya no se consigue cocaína, pues se ha convertido en una droga de lujo, en su lugar llegó y se instaló el cristal, que se regala y se vende en dosis que van desde los veinte pesos. Es una droga para pobres, con alto potencial adictivo y gran cantidad de efectos secundarios que mina la salud física y mental de los jóvenes usuarios y para la cual no se ofrece una alternativa terapéutica diferente a la abstinencia.

Siguiendo a Merton (1995 [1938]), los jóvenes como Vicente han constatado la desvinculación entre el trabajo y el progreso económico y social. Se niegan a participar en un mercado laboral que ofrece un nivel de ingresos insuficiente para sus expectativas de vida y en el que además no son elegibles por su apariencia física, por sus antecedentes penales, falta de comprobantes de identidad, incluida su identificación oficial y/o, no contar 
con la capacitación requerida. Sin embargo, no renuncian a su aspiración de tener los bienes de consumo que desean, y tampoco quieren ser excluidos ni marginales. Para Vicente, el uso de la violencia se constituyó en un recurso individual para obtener movilidad ascendente, aunque fuera efímera. Vicente es uno de los miles de jóvenes en México para quienes "vender riesgo" es su única alternativa frente a la exclusión, el único capital con el que cuentan es su propio cuerpo (Reguillo, 2012b, 2013). Esos cuerpos jóvenes se entregan con igual intensidad a un ataque a muerte con otro grupo armado (legal o ilegal), que a la experiencia límite de un uso intenso de drogas.

\section{CONSIDERACIONES FINALES}

Los tres relatos aquí presentados ilustran los cambios en las dinámicas de compraventa de drogas y en el mercado local de drogas en los sectores pobres del norte de Hermosillo entre 1970 y 2016. Particularmente, la lectura transgeneracional de los relatos evidencia cómo han cambiado los tipos de drogas que se comercializan en este sector de la ciudad, los intermediarios a través de los cuales llegan las drogas a las colonias, los cambios en las relaciones entre distribuidores y usuarios, el tipo de relación que los usuarios de cada generación establecen con las policías, y el tipo de vinculación que establecen con grupos y actores criminales que posibilitan la disponibilidad de drogas en este sector de la ciudad.

Los cambios relatados por los participantes en las dinámicas de compraventa y uso de drogas muestran cómo se expresan en el tiempo individual los cambios sociales descritos en el breve recuento sobre la historia de los procesos de producción y comercialización de drogas ilegales en el país, y las especificidades con las que se traduce esta historia social en el contexto de Hermosillo. El relato deja ver cómo el aumento de la presencia militar y policial no sólo no ha logrado desincentivar el dinamismo de los mercados locales de drogas, sino que ha aumentado las muertes y la criminalización de los jóvenes pobres.

Analizados en clave generacional, los relatos biográficos de Rafael, Aurelio y Vicente muestran la manera en que se han ido agudizando las condiciones de empobrecimiento de las familias que habitan la zona norte de Hermosillo entre una y otra generación, cómo ha aumentado la marginalidad de los jóvenes de este sector de la ciudad y cómo se ha hecho presente de manera diferenciada la delincuencia organizada. Esta mayor presencia del crimen organizado ha transformado las formas de sociabilidad del barrio, las opciones de generación de ingresos y los referentes de identidad de los jóvenes varones, así como las dinámicas de compraventa y uso de drogas.

Si bien los tres participantes se enfrentaron a condiciones de escasez económica y al estigma de "adicto" debido a su uso de drogas, el tipo de actores a través de los cuales se aprovisionaban de las drogas que usaban, los expuso a niveles diferenciados de violencia en el marco de dinámicas particulares de compraventa y uso de drogas en cada generación y marcó diferencias en sus trayectorias criminales. El uso de la violencia está menos presente en el relato de Rafael, el participante de la generación mayor, y se torna en un elemento cada vez más importante en la construcción de las identidades de los usuarios más jóvenes 
22 Cambios en las dinámicas de compraventa y uso de drogas. Un análisis generacional...

Ospina Escobar, A. M.

y como forma fundante de las relaciones con los otros, sus pares, las instituciones y/o sus rivales. Adicionalmente, las trayectorias delictivas de las generaciones más jóvenes se caracterizaron por iniciarse con delitos de mayor intensidad (homicidios) y estar marcadas por la experiencia temprana de ingreso a prisión (antes de los 18 años), lo que generó en los sujetos más jóvenes, mayores dificultades de inclusión social y mayor afianzamiento en las trayectorias delictivas.

En un mundo donde cada vez más las identidades se construyen en torno a la apariencia y el consumo, el ingreso al crimen organizado, aún en sus eslabones más bajos, le ofrece a los jóvenes pobres una ventana de oportunidad para alcanzar sus expectativas. A medida que la sociedad se torna más desigual, que la exclusión se hace más radical y los espacios de sociabilidad se erosionan, el recurso de la violencia se va haciendo más y más funcional en la búsqueda de respeto y lugar en el mundo.

El estigma construido frente al "adicto" y el discurso de la falla del "yo" que lo acompaña, invisibiliza que en la configuración de los destinos fatales asociados a los varones pobres que viven una condición de uso problemático de drogas, juega un rol importante las violencias institucionales y morales que enfrentan estos jóvenes a lo largo de sus biografías, la desigualdad y la segregación social. Estos jóvenes encarnan la contradicción más aguda del capitalismo, pues son portadores de valores e ideales impuestos por el mismo sistema que los excluye de sus beneficios, pero perversamente se lucra de sus aspiraciones de inclusión. El estigma y la exclusión convierte a estos jóvenes en soldados desechables que luchan a muerte a cambio de drogas y distinción. Sus muertes y su dependencia a las drogas sólo importan para sus familias, cuando las tienen, pues constituían una población excedente mucho antes de su dependencia a las drogas y de haber encontrado en la violencia una forma de vida y de construcción de sí mismos.

\section{REFERENCIAS}

Arredondo, Í. (3 de marzo de 2018). "Cristal en las venas”. El Universal. Informe especial. Revisado el 1 de octubre de 2018. Recuperado de http://interactivo.eluniversal.com.mx/2018/cristal-droga/

Astorga, L. (2015). Drogas Sin Fronteras. México: De Bolsillo.

Astorga, L. (2007). Seguridad, traficantes y militares. El poder y la sombra. México: Tusquets.

Atuesta Becerra, L.H. (2018). "Militarización de la lucha contra el narcotráfico: Los operativos militares como estrategia para el combate al crimen organizado" En Atuesta Becerra, L.H. y Madrazo, A. (Eds.), Las violencias: En busca de la política pública detrás de la guerra contra las drogas, (pp 91-132). México: Centro de Investigación y Docencia Económicas. 
Bertaux, D. (1983). "From the Life-History Approach to the Transformation of Sociological Practice" En Bertaux, D. (comp.) Biography and Society. The Life History Approach in the Social Sciences, (pp. 28-46). Berkeley: Sage Publications.

Camberos, M. (2000). "Pobreza, desempleo y deuda pública ¿expectativas para Sonora en el Siglo XXI". En Almada Bay, I. (Ed.), Sonora 2000 a debate. Problemas y soluciones, riesgos y oportunidades, (pp. 251-256). México: El Colegio de Sonora/Aguilar/León/Cal Editores.

Camberos, M. y Yáñez, J. (2003). La informalidad de los mercados laborales de Sonora y la frontera norte de México. Revista Región y Sociedad, 15(27), 153-178.

Centro Nacional para la Prevención y Control del Sida (Censida, 2010). Tamaño estimado de población HSH y UDIS en las ciudades prioritarias de propuesta Ronda 9. Documento inédito.

Chase, S. (2005). "Narrative Inquiry. Multiple lenses, approaches, voices". En Denzin N. y Lincoln Y. (eds.) Collecting and interpreting qualitative materials. (pp. 57-94). Oaks: Sage Publications.

Ciccarone, D., Unick, G., y Kraus, A. (2009). Impact of South American heroin on the US heroin market 1993-2004. International Journal of Drug Policy, 20(5), 392-401.

Constitución Política de los Estados Unidos Mexicanos. (2017). Recuperado de http://www.diputados.gob.mx/LeyesBiblio/pdf/1_150917.pdf

Covarrubias, A. (1990). La economía: Crisis y reestructuración de la producción y el capital. Revista de El Colegio de Sonora, (2), 1-51.

Covarrubias, A. (2000). La viabilidad económica de Sonora. En Almada Bay, I. (Ed.), Sonora 2000 a debate. Problemas y soluciones, riesgos y oportunidades, (pp. 101156). México.: El Colegio de Sonora/Aguilar/León/Cal Editores.

García, A. (2013). Factorías del crimen organizado: México y Colombia, oleadas o persistencia de la violencia. Sociología Histórica, (2), 355-380.

Goffman, Erving (2006). Estigma. La identidad deteriorada. Buenos Aires: Amorrortu Editores.

Instituto Nacional de Estadística y Geografía, Inegi (2018a). Estadísticas de Mortalidad. Defunciones por homicidios según ciudad de registro. Recuperado de: http://www.inegi.org.mx/sistemas/olap/proyectos/bd/continuas/mortalidad/defuncio neshom.asp?s=est revisado el 10 de enero de 2018

Inegi (2018b). Incidencia delictiva. Delitos Sentenciados por Entidad Federativa y Municipio. Recuperado de http://www.beta.inegi.org.mx/temas/incidencia/

Inegi (2015). Escolaridad. $\quad$ Recuperado de http://cuentame.inegi.org.mx/poblacion/escolaridad.aspx?tema=P

Inegi (2010). XII Censo general de población y Vivienda. Recuperado de http:/www.beta.inegi.org.mx/temas/empleo/ 
Knight, A. (2012). Narco-Violence and the State in Modern Mexico. En W. G. Pansters, Violence, Coercion, and State-Making in Twenieth-Century Mexico: The Other Half of the Centaur, (pp. 115-134). California: Standford University Press.

Lara Enríquez, B. E. (1990). La industria maquiladora y la pequeña, mediana y microindustria. ¿Reestructuración y polarización? Revista de El Colegio de Sonora, II(2), 75-102.

Link, B. y Phelan, J.C. (2001). Conceptualizing Stigma. Annual Review of Sociology, 27, 363-385.

Martínez Salgado, C. (2012). El muestreo en investigación cualitativa. Principios básicos y algunas controversias. Ciencia \& Saude Colectiva, 17(3), 613-619.

Merton, R. (1995[1938]). Social Structure and Anomie. American Sociological Review, $3(5), 672-682$.

Nill Sánchez, A. (2013). Mexico's Drug "War": Drawing a Line Between Rhetoric and Reality. The Yale Journal of International Law, 38(2), 467-509.

Ochoa, M. (2017) Del crimen organizado al crimen desordenado: una apuesta por la observación conceptual y contextual. Desacatos, 54, 92-105.

Ospina Escobar, A. (2016). Itinerarios de adversidad. Biografías de uso de drogas, estilos de vida y ambientes de riesgo al VIH en varones inyectores de Tijuana, Cd. Juárez y Hermosillo, México. (Tesis de doctorado en Estudios de Población). El Colegio de México, México.

Payá, V. (2006) Vida y muerte en la cárcel. Estudio sobre la situación institucional de los prisioneros, México: UNAM/Plaza y Valdés.

Reguillo, R. (2013). Jóvenes en la encrucijada contemporánea: En busca de un relato de futuro. Debate feminista, 48, 137-151.

Reguillo, R. (2012a). De las violencias: Caligrafía y gramáticas del horror. Desacatos, (40), 33-46.

Reguillo, R. (2012b). Memories of the future. Young, 20(4), 345-355.

Reguillo, R. (2010). La condición juvenil en el México contemporáneo. Biografías, incertidumbres y lugares. En Reguillo, R. (Coord.), Los jóvenes en México (pp. 395429). México: Fondo de Cultura Económica-Consejo Nacional para la Cultura y las Artes

Ríos Contreras, V. (2012). How Government Structure Encourages Criminal Violence: The causes of Mexico's Drug War. A dissertation for the degree of Doctor of Philosophy in the subject of Political Science. Cambridge, Massachusetts: Harvard University.

Romaní, O. (2010). Adicciones, drogodependencias y "problema de la droga" en España: la construcción de un problema social. Cuicuilco. Escuela Nacional de Antropología e Historia, 17(49), 83-101.

Sanderson, S. (1981). Agrarian Populism and the Mexican State. Berkley: University of California Press. 
Secretaría de Salud. Subsecretaría de prevención y promoción de la salud. (2018). Sistema de Vigilancia Epidemiológica de las Adicciones (SISVEA). Informe 2017. México: Secretaría de Salud.

Secretaría de Salud. Subsecretaría de prevención y promoción de la salud. (2008). Sistema de Vigilancia Epidemiológica de las Adicciones (SISVEA). Informe 2007. México: Secretaría de Salud.

Secretaría de Salud. Subsecretaría de prevención y promoción de la salud. (2015). Sistema de Vigilancia Epidemiológica de las Adicciones (SISVEA). Informe 2014. México: Secretaría de Salud.

Serrano, M. (2007). México: narcotráfico y gobernabilidad. Pensamiento Iberoamericano (1), 251-278.

Urteaga, M. (2010). Género, clase y etnia. Los modos de ser joven. En Reguillo, R. (Coord.), Los jóvenes en México (pp.15-51). México: Fondo de Cultura Económica-Consejo Nacional para la Cultura y las Artes.

Valenzuela, J. M. (2010). Juventudes desmediadas. Desigualdad, violencia y criminalización de los jóvenes en México. En Reguillo, R. (Coord.), Los jóvenes en México (pp. 316-349). México: Fondo de Cultura Económica-Consejo Nacional para la Cultura y las Artes.

Valenzuela, J. M. (2009). El futuro ya fue. Socioantropología de l@s jóvenes en la modernidad. Tijuana: El Colegio de la Frontera Norte/Casa Juan Pablos.

Villatoro-Velázquez, J., Oliva Robles, N., Fregoso Ito, D., Bustos Gamiño, M., Mujica Salazar, A., Martín del Campo Sánchez, R., Nanni Alvarado, R., Medina-Mora, M.E., (2015). Encuesta Nacional de Consumo de Drogas en Estudiantes 2014 (Encode 2014). Reporte de Drogas. México: Instituto Nacional de Psiquiatría Ramón de la Fuente Muñiz. 